\title{
Peranan Edukasi Bidan dalam Mencegah Kurang Energi Kronis (KEK) pada Ibu Hamil di Provinsi Sulawesi Tengah
}

\author{
Sri Restu Tempali*, Sumiaty \\ Jurusan Kebidanan, Poltekkes Kemenkes Palu \\ *Email korespondensi: srirestu@gmail.com
}

Article Info

Article history:

Submitted: 2019-02-19

Accepted: 2019-04-16

Published: 2019-04-22

Keywords:

Role of Education; Midwives;

Chronic Energy

Deficiency;

Pregnancy
Basic Health Research in 2013 recorded the prevalence of Chronic Energy Deficiency (SEZ) in pregnant women nationally reaching 24.2 percent, an increase from 2010 (18.8\%\%) and 2007 (10.9\%). The prevalence of SEZs in Central Sulawesi Province in 2013 was $32.6 \%$, higher than the National average. Nutritional status monitoring in Central Sulawesi Province reported a prevalence of KEK Risk in pregnant women in 2015 of $32.6 \%$. Districts with the highest prevalence were consecutively in Banggai Kepulauan District $(67.8 \%)$, Tojo Una-Una District (51.9\%), Sigi District (46.4\%), Donggala District $(36.7 \%)$, and Palu City (35.4\%). Midwives in providing services to the community, especially pregnant women, always strive to prepare pregnant women since the first contact during prenatal care provides counseling or education to every pregnant mother about nutritional needs during pregnancy. This study aims to determine the role of midwifes education in preventing SEZ in pregnant women in Central Sulawesi Province. Observational research with astudy design crosectional. Sampling using the proportional random sampling technique with a total sample of 98 midwives in the working area of 4 selected districts, namely Banggai Islands District (15 samples), Sigi District (18 samples), Donggala District (25 samples) and Palu City (40 samples). The results of the study showed that the midwives who carried out the role of education to pregnant women in their regions mostly did not have the incidence of pregnant women with SEZ (83.1\%). The results of theanalysis Chi-Square obtained a p-Value value of 0.041 , which means that there is a relationship between the role of midwife education and prevention of SEZ events in pregnant

\section{PENDAHULUAN}

Gizi merupakan salah satu faktor penentu utama kualitas sumber daya manusia. Gangguan gizi pada awal kehidupan akan mempengaruhi kualitas kehidupan berikutnya. Gizi ibu hamil adalah nutrien yang diperlukan dalam jumlah yang lebih besar dari pada jumlah yang dibutuhkan orang dewasa normal karena pada masa hamil pemenuhan status gizi untuk ibu sendiri dan untuk perkembangan bayi yang dikandungnya. ${ }^{1}$ Kebutuhan gizi selama kehamilan akan meningkat hingga 300 kalori perhari, meskipun semua orang di Indonesia sudah mengetahui manfaat gizi bagi ibu hamil namun sampai saat ini masih banyak ibu hamil yang mengalami masalah gizi khususnya gizi kurang seperti Kurang Energi Kronis atau KEK. ${ }^{2}$ KEK selama hamil akan menimbulkan masalah, baik pada ibu maupun janin. KEK pada ibu hamil dapat menyebabkan risiko dan komplikasi pada ibu antara lain: anemia, pendarahan, berat badan ibu tidak bertambah secara normal dan terkena penyakit 
infeksi. Pengaruh KEK terhadap proses persalinan dapat mengakibatkan persalinan sulit dan lama, persalinan sebelum waktunya (prematur), pendarahan setelah persalinan, serta persalinan dengan operasi cenderung meningkat ${ }^{3}$

KEK ibu hamil dapat mempengaruhi proses pertumbuhan janin dan dapat menimbulkan keguguran,abortus, bayi lahir mati,kematian neonatal,cacat bawaan,anemia pada bayi, asfiksia intra partum,lahir dengan BBLR. ${ }^{3}$ Pemantauan status gizi di Provinsi Sulawesi Tengah melaporkan prevalensi Risiko KEK pada ibu hamil tahun 2015 sebesar 32,6\%. Kabupaten dengan prevalensi tertinggi berturut turut di Kabupaten Banggai Kepulauan (67,8\%), Kabupaten Tojo Una-Una (51,9\%), Kabupaten Sigi $(46,4 \%)$, Kabupaten Donggala $(36,7 \%)$, dan Kota Palu $(35,4 \%){ }^{4}$

Upaya yang dapat dilakukan bidan berdasarkan Keputusan Menteri Kesehatan Republik Indonesia nomor 369 tahun 2007 tentang standar profesi bidan mengenai intervensi ibu hamil dengan KEK, yaitu melakukan rujukan ke petugas tenaga gizi dan berkolaborasi untuk membantu memonitoring serta mengevaluasi asupan pemberian makanan dan kenaikan berat badan. ${ }^{5}$

Upaya lainnya dalam menanggulangi masalah dan mencegah dampak dari kurang energi kronis pada ibu hamil yaitu mengusahakan agar ibu hamil memeriksakan kehamilan secara rutin sejak hamil muda untuk mendeteksi secara dini kejadian kurang energi kronis, dan penyuluhan tentang asupan nutrisi yang dibutuhkan ibu hamil.Bidan dalam memberikan pelayanan kepada masyarakat, khususnya ibu hamil, senantiasa berupaya mempersiapkan ibu hamil sejak kontak pertama saat pemeriksaan kehamilan untuk mencegah terjadinya KEK pada Ibu hamil. Tujuan penelitian untuk mengetahui peran edukasi bidan dalam mencegah Kurang Energi Kronis (KEK) pada ibu hamil di Provinsi Sulawesi Tengah.

\section{METODE PENELITIAN}

Penelitian ini merupakan penelitian observasional dengan desain crosssectional. Penelitian ini dilakukan di wilayah Kabupaten Banggai Kepulauan (Bangkep), Kabupaten Touna, Kabupaten Sigi, Kabupaten Donggala, dan Kota Palu. Pemilihan lokasi penelitian didasarkan pada daerah dengan prevalensi kurang energi kronik (KEK) tertinggi di Sulawesi Tengah, Penelitian dilaksanakan selama kurang lebih 3 bulan, 3 Juli s/d 4 September 2017. Populasi dalam penelitian ini adalah seluruh bidan yang berjumlah Jumlah sampel sebanyak 400 bidan. Jumlah sampel 98 dengan penentuan sampel dengan teknik simple random sampling. Analisis statistik menggunakan uji chi-square.

\section{HASIL PENELITIAN}

Hasil pengolahan data dapat disajikan sebagai berikut:

Tabel 1. Distribusi Frekuensi Seluruh Responden berdasarkan peran edukasi bidan dan KEK di Sulawesi Tengah

\begin{tabular}{ccc}
\hline Variabel & Frekuensi & Persentase (\%) \\
\hline Peran Edukasi Bidan & 9 & 9,2 \\
Tidak Berperan & 89 & 90,8 \\
Berperan & & \\
Kurang Energi Kronis (KEK) & 19 & 19,4 \\
KEK & 79 & 80,6 \\
Tidak KEK & & \\
\hline
\end{tabular}

Sumber: Data primer, 2017 
Pada tabel 1 menunjukkan bahwa sebagian besar Bidan telah melakukan perannya dalam melakukan edukasi dalam mencegah kekurangan energi kronik (KEK) selama ibu hamil $(90,8 \%)$, dan sebagian besar ibu hamil yang berada diwilayah kerja Bidan menunjukkan bahwa ibu hamil selama kehamilannya tidak mengalami kekurangan energi kronik (KEK) (80,6\%).

Tabel 2. Hubungan Peranan Edukasi Bidan Dalam Mencegah Kurang Energi Kronis (KEK) Pada Ibu Hamil di Sulawesi Tengah

\begin{tabular}{|c|c|c|c|c|c|c|}
\hline \multirow{3}{*}{ Peranan Edukasi Bidan } & \multicolumn{4}{|c|}{ Kurang Energi Kronis (KEK) } & \multirow{3}{*}{ Nilai $p$} & \multirow{3}{*}{ OR } \\
\hline & \multicolumn{2}{|c|}{ KEK } & \multicolumn{2}{|c|}{ Tidak KEK } & & \\
\hline & $\mathbf{f}$ & $\%$ & $\mathbf{f}$ & $\%$ & & \\
\hline Tidak Berperan & 4 & 44,4 & 5 & 55,6 & \multirow{3}{*}{0,041} & \multirow{3}{*}{$\begin{array}{c}3,9 \\
(2,3-15,4)\end{array}$} \\
\hline Berperan & 15 & 16,9 & 74 & 83,1 & & \\
\hline Jumlah & 19 & 19,4 & 79 & 80,6 & & \\
\hline
\end{tabular}

Sumber: Data primer, 2017

Pada tabel 2 menunjukkan bahwa bidan yang melakukan peran edukasi kepada ibu hamil diwilayahnya sebagian besar tidak memiliki kejadian ibu hamil dengan KEK (83,1\%). Hasil analisis Chi-Square hubungan peran edukasi bidan dalam mencegah KEK yaitu sebagai berikut. diperoleh nilai p sebesar 0,041, yang artinya bahwa ada hubungan antara peran edukasi bidan dengan pencegahan kejadian KEK pada ibu hamil selama kehamilan

\section{PEMBAHASAN}

Penelitian ini bertujuan untuk mengetahui peran edukasi bidan dalam mencegah Kurang Energi Kronis (KEK) pada ibu hamil di Provinsi Sulawesi Tengah. Hasil penelitian menunjukkan bahwa ada hubungan antara peran edukasi bidan dengan rendahnya kejadian KEK ( $p$-Value=0,041). Bidan yang berperan mengedukasi para ibu hamil selama kehamilannya memiliki peluang 3 kali dalam mencegah terjadinya kekurangan energi kronik pada ibu hamil selama kehamilannya $(\mathrm{OR}=3,9)$.

Hal ini telah sesuai dengan wewenang bidan yang telah diamanahkan pada Kepmenkes RI nomor 369 tahun 2007 tentang standar profesi bidan yang berkaitan dengan intervensi ibu hamil dengan KEK, bahwa upaya yang dapat dilakukan bidan yaitu melakukan kolaborasi dengan petugas gizi dalam kegiatan monitoring dan evaluasi asupan pemberian makanan dan kenaikan berat badan ibu hamil selama kehamilannya serta melakukan rujukan ke petugas tenaga gizi apabila ada ibu hamil yang memerlukan penanganan khusus. ${ }^{5}$

Peran edukasi yang dilakukan bidan meliputi konseling tentang pentingnya nutrisi selama kehamilan, komposisi nutrisi yang baik dan dibutuhkan selama kehamilan, pemeriksaan kehamilan secara teratur khususnya penimbangan berat badan dan pengukuran lingkar lengan atas (LILA), cara pengolahan makanan tambahan dan daftar makanan penukar yang disesuaikan dengan bahan makanan lokal.

Hal ini sesuai dengan penelitian King (2003) yang menyatakan bahwa dalam penyediaan makanan yang mengandung cukup gizi, faktor lingkungan sangat mempengaruhi dan berdampak pada bayi yang dilahirkan. Jika seorang wanita kekurangan gizi akan mengganggu proses reproduksinya dan bila dalam masa 
kehamilan akan menghambat pertumbuhan janin, kelahiran preterm, lahir mati dan kematian ibu. ${ }^{6}$

Terkait pentingnya status gizi ibu hamil terhadap pertumbuhan janin maka status gizi ibu hamil harus benar-benar mendapat perhatian. Hal ini sejalan dengan penelitian dari Susilani $A$, (2014) yang mengatakan bahwa gizi yang baik sangat diperlukan oleh ibu hamil agar pertumbuhan janin tidak mengalami hambatan, sehingga dapat melahirkan bayi dengan berat badan normal. ${ }^{7}$ Dengan kondisi kesehatan yang baik, sistem reproduksi normal, tidak menderita sakit, dan tidak ada gangguan gizi pada masa pra hamil maupun saat hamil, ibu akan melahirkan bayi yang lebih sehat.

Pada upaya pencegahan KEK, Bidan hendaknya memberikan edukasi kepada ibu sedini mungkin, yaitu dengan melakukan edukasi melalui edukasi prenatal. Hal ini didukung oleh Penelitian Lu et al. (2003) yang menyatakan bahwa edukasi kesehatan dapat memberikan informasi tentang pengaruh kehamilan, perubahan fisik selama hamil dan informasi perawatan bayi sehingga ibu akan percaya diri menghadapi persalinan. ${ }^{8}$ Penelitian Ambarwati \& Sintowati (2006) juga menyatakan bahwa edukasi kesehatan yang diberikan oleh petugas kesehatan kepada ibu hamil dapat meningkatkan pengetahuan dan perubahan sikap dalam mengatasi keluhan selama kehamilan. ${ }^{9}$

Hal ini sesuai dengan hasil penelitian Totten et al. (2003) bahwa edukasi prenatal dapat mempengaruhi perubahan prilaku gaya hidup yang positif pada wanita hamil, meningkatkan pengetahuan yang berhubungan dengan kehamilan, perawatan bayi serta dapat meningkatkan rasa percaya diri ibu dalam menghadapi persalinan dan kelahiran bayinya. ${ }^{10}$

Model edukasi bidan dalam pendidikan prenatal yaitu menggunakan paket Kelas Ibu Hamil yaitu Buku KIA, flip chart (lembar balik), pedoman pelaksanaan kelas ibu hamil, pegangan fasilitator kelas ibu hamil dan buku senam ibu hamil. Model edukasi yang dapat diterapkan oleh bidan sebagai salah satu bagian dari strategi perubahan perilaku menurut WHO dalam Notoatmodjo, 2007 adalah diskusi partisipasi yaitu salah satu cara pemberian informasi tentang kesehatan yang tidak bersifat searah saja tetapi dua arah, yang berarti ibu hamil tidak hanya pasif menerima informasi, tetapi juga harus aktif berpartisifasi melalui diskusi-diskusi tentang informasi yang diterimanya. ${ }^{11}$

\section{SIMPULAN DAN SARAN}

Kesimpulan berdasarkan hasil penelitian dapat disimpulkan bahwa ada hubungan antara peran edukasi bidan dalam mencegah kekurangan energi kronik pada ibu hamil di provinsi Sulawesi Tengah. Bidan yang berperan mengedukasi para ibu hamil selama kehamilannya memiliki peluang 3 kali dalam mencegah terjadinya kekurangan energi kronik pada ibu hamil selama kehamilannya $(\mathrm{OR}=3,9)$. Dan disarankan kepada petugas kesehatan khususnya Bidan hendaknya memberikan edukasi kepada ibu sedini mungkin, yaitu dengan melakukan edukasi prenatal. model edukasi yang dapat diterapkan oleh bidan sebagai salah satu bagian dari strategi perubahan perilaku. Bidan dapat melakukan kegiatan secara mandiri seperti edukasi pola makan, pemberian makanan tambahan, melakukan monitoring dan melakukan evaluasi apabila tidak ada petugas gizi pada wilayah tempat ia bertugas.Bidan hendaknya melakukan kolaborasi dengan petugas gizi dalam kegiatan monitoring dan evaluasi asupan pemberian makanan dan kenaikan berat badan ibu hamil selama kehamilannya serta melakukan rujukan ke petugas tenaga gizi apabila ada ibu hamil yang memerlukan penanganan khusus. 


\section{DAFTAR PUSTAKA}

1. Bobak, Lowdermik, Jensen. Buku Ajar Keperawatan Materntas. 4 ed. Jakarta: EGC; 2005.

2. Damanik NE. Gambaran Konsumsi Makanan dan Status Gizi Pada Anak Penderita Karies Gigi di SDN 091285 Panei Tongah Kecamatan Panei. Universitas Sumatera Utara; 2009.

3. Proverawati A. Buku Ajar Gizi Untuk Kebidanan. Yogjakarta: Nuha Medika; 2010.

4. Dinas Kesehatan Propinsi Sulawesi Tengah. Profil Kesehatan Sulawesi Tengah Tahun 2014. Palu; 2015.

5. Kementerian Kesehatan R.I. Keputusan Menteri Kesehatan Republik Indonesia No. 369 MENKES/SK/III/2007 tentang Standar Profesi bidan. 2007.

6. King JC. The Risk of Maternal Nutritional Depletion and Poor Outcomes Increases in Early or Closely Spaced Pregnancies. J Nutr [Internet]. 1 Mei 2003;133(5):1732S1736S. Tersedia pada: https://academic.oup.com/jn/article/133/5/1732S/4558575

7. Susilani AT. Hubungan Ukuran Lingkar Lengan Atas Ibu dengan Berat Badan Lahir. J Permata Indones. 2016;6(1).

8. Lu MC, Prentice J, Yu SM, Inkelas M, Lange LO, Halfon N. Childbirth Education Classes Sociodemographic Disparines in Attendance and the Association of Attendance With Breast Feeding Intiation. Matern Child Health J [Internet]. Juni 2003;7(2):87-93. Tersedia pada: http://www.ncbi.nlm.nih.gov/pubmed/12870624

9. Ambarwati WN, Sintowati R. Pengaruh Pendidikan Kesehatan mengatasi Keluhan Hamil terhadap Perubahan Pengetahuan, Sikap dan Perilaku Ibu-ibu hamil di Asrama Group II Kopasus Kartasura. Warta2 [Internet]. 2006;9(2). Tersedia pada: https://publikasiilmiah.ums.ac.id/bitstream/handle/11617/1092/1.

WINARSIH.pdf;sequence=1

10. Totten S., Steel O'Connor S., Choremiotis P., Jeswiet J. \& MK. Evaluation of the KFL\&A Health Unit Prenatal Education Program. 2003.

11. Notoatmodjo S. Promosi Kesehatan dan IImu Perilaku. Jakarta: Rineka Cipta; 2007. 